\title{
Autologous GM-CSF-secreting Lethally Irradiated Leukemia Cell Vaccine
}

National Cancer Institute

\section{Source}

National Cancer Institute. Autologous GM-CSF-secreting Lethally Irradiated Leukemia Cell

Vaccine. NCI Thesaurus. Code C104419.

An autologous cancer vaccine composed of lethally irradiated leukemia cells that are genetically modified to secrete the immunostimulatory cytokine granulocytemacrophage colony-stimulating factor (GM-CSF), with potential immunostimulating and antineoplastic activities. Upon intradermal injection, the autologous GM-CSF-secreting lethally irradiated leukemia cell vaccine secretes GM-CSF. In turn, GM-CSF may stimulate the immune system to attack tumor cells by enhancing the activation of dendritic cells (DCs) and promoting antigen presentation to both B- and T-lymphocytes. In addition, GM-CSF promotes antibody-dependent cellular cytotoxicity (ADCC), and increases interleukin-2-mediated lymphokine-activated killer cell function. 